\title{
Immobilised Aquaprobiotics of Marine Microbial Origin and their Efficacy.
}

\section{Jayaprada Rao Chunduri*, Nikita Vikas Singhi}

Department of Biotechnology, Mithibai College of Arts, Chauhan Institute of Science, A.J. College of Commerce and Economics, Vile Parle(W), Mumbai 400056, India

Study Area: Mumbai Coast, India

Coordinates: Latitude19.0760 ${ }^{\circ} \mathrm{N} ; 72.8777^{\circ} \mathrm{E}$
Key words: Marine bacteria, PSBs

\section{Abstract}

Marine waters contain millions of disease-causing and friendly bacteria which have the capacity to solubilize the insoluble compounds. Such live bacteria are of use to improve the health of wastewaters and their quality. Phosphate solubilizing bacteria solubilize the insoluble phosphate by digesting the compounds which can be considered as aquaprobiotics. An attempt has been made to isolate and characterize the phosphate solubilizing bacteria from the Indian coastal waters. Their capability to remediate the waste waters rich with phosphates. Assessed. Microbiological analysis and molecular identification conf irmed that two isolates among the seven variants were Gram-positive and belonged to Klebsiella spp. The immobilized PSBs with sodium alginate on different inert substrata were tested for their phosphate solubilizing activity in the wastewaters. The study indicated that both variants have good capability, increased longevity, and reusable conditions. PSB based aquaprobiotics can be of great use in the treatment of waste waters and plants.

\section{Introduction:}

Marine biodiversity is one of the important areas of current interest for its importance in future applications. Biotic life of marine ecosystem comprises different species of organisms from bacteria to mammals. Marine waters are considered as reservoirs for microbial organisms can be pathogenic bacteria viz. Vibrio spp., Salmonella and Shigella spp., as well as beneficial one too. Earlier research indicated that bacteria can help in wastewater treatment and bioremediation purposes (De Souza et. al., 200o). Microorganisms especially bacteria play a vital role in the biogeochemical cycling of nutrients in the marine environment. Most of the phosphate and nitrate incorporated into the aquatic plants, animals, and sediments are due to the action of the microbes. They are also responsible for decomposing dead organic matter and recycling of phosphorus (Ayyakkunnu \& Chandramohan, 1970; De Souza et. al.,2000). Bacterial action and autolysis, as well as excretion of living zooplankton, are believed to account for the degradation of organic phosphorus(Illmer \& Schinner, 1995; Ahamed \& Shahab, 2011). While inorganic phosphate is generally regarded as the most bioavailable form of phosphorus, its concentration in the surface waters of the open ocean is much smaller than that of dissolved organic phosphorus (DOP) (Das et. al., 2007; Dyhrman et. al.,2007). Phosphorus is an essential nutrient to all life, as well as a structural and functional component of organisms. Large quantities of elemental phosphorus are immobilized in the living organism or locked up in the sediments as insoluble organic and inorganic compounds. Phosphate solubilizing bacteria (PSB) are a group of bacteria which solubilize the insoluble phosphate into soluble forms. It can be a source of nutrient as well for other organisms. Many different types of PSBs such as Pantoea agglomerans, Microbacterium laevaniformans and Pseudomonas putida strains are identified and, immense data on species of Bacillus spp., Shigella spp., Vibrio spp. etc.is available (Mamatha et al., 2012; De et.al.,2011).

Phosphophate solubilizing bacteria have been found to produce some organic acids such as Phosphate solubilizing bacteria have been found to produce some organic acids that solubilize phosphates such as citric, lactic, gluconic, 2-ketogluconic, oxalic, glyconic, acetic, malic, fumaric, succinic, tartaric, malonic, glutaric, propionic, butyric, glyoxalic, and adipic acids (Kalayu, 2019). Phosphate solubilization seems to be a complex biochemical phenomenon and it is important to understand the bacterial populations capable of Phosphate 
solubilization, realizing the multiple roles the native bacteria perform (Kannapiran \& Sri Ramkumar, 2011). There are many other various mechanisms which are being proposed for a better understanding of solubilization of phosphate by PSB. Wastewater from domestic, commercial, industrial and other sources contain a lot of pollutants in them. Inorganic insoluble phosphate is one such pollutant which is majorly present in the wastewater. Organic phosphorus mineralizing bacteria (OPB) play an important role in phosphorus cycling in lake sediment, to which less attention has been paid. (Chun et al., 2011; Das et.al., 2007; Zhou e al.,2011). There have been studies showing bacterial biodegradation of insoluble phosphate in wastewater which was isolated different aquatic environments (Kumar et.al., 2007; Dipak \& Sankar, 2017; Yulianti \& Rakhmawati 2017; Maitra et.al., 2014; Mamatha et.al., 2012). Similarly, PSBs were identified among rhizosphere microbial community in mangroves (Vazquez et.al., 200o; Audipudi et.al., 2012) and even treatment plants (Martinez \& Yaneth, 2009). In the current study, types of PSB were isolated from coastal waters and found to be active in solubilizing phosphates in encapsulated form from wastewaters. Thus, it can be considered PSBs as "aquaprobiotics" that improve the health of wastewater by treating it and thus reducing the insoluble phosphate quantities in it.

\section{Materials and methods:}

Sampling: the surface sand and water samples were collected in triplicates from three selected stations - Mud island, Versova and Chaupati beaches in Mumbai along an intertidal regions in sterile glass bottles. Samples were immediately transported to the laboratory in the icebox and preserved at $4^{\circ} \mathrm{C}$ until further analysis.

Isolation of the bacteria: the samples were serially diluted to 10-4 and were plated on the Nutrient Agar to obtain the overall count of the bacterial colonies and on selective medium (Pikovskaya's agar). The colonies with a zone of inhibition on the Pikovskaya's agar after an incubation of 24-47 hours at room temperature were identified and isolated. These isolates were further considered for microscopic, Gram Staining and further studies. The isolates on Nutrient agar slants were considered for molecular identification. CTAB method of DNA was extraction followed by PCR analysis and identification of species (Sambrook \& Russel, 2001) was carried out. Phosphate estimation: Phosphate was estimated as per Fiske- Subbarow method (Fiske \& Subba, 1925). Potassium dihydrogen phosphate was considered a standard $(10 \mu \mathrm{g} / \mathrm{ml})$. The absorbance of test and standards were read at $650 \mathrm{~nm}$ after $10 \mathrm{~min}$ incubation at room temperature using Equiptron 650 colorimeter.

Phosphate Bioremediation Efficacy Estimation: the isolates were checked for their phosphate solubilizing efficacy in various media using flask studies by non encapsulated and encapsulated forms.

a) Non-encapsulated form:overnight cultures were inoculated in synthetic phosphate and artificial phosphate media. $10 \mathrm{ml}$ of the 0.1 OD culture inoculum was added to 100 $\mathrm{ml}$ of each medium and kept on the rotatory shaker at $37^{\circ} \mathrm{C}$. Further, $5 \mathrm{ml}$ of the medium was taken out aseptically each time, centrifuged at $10000 \mathrm{rpm}$ for 10 minutes, and the supernatant was considered for analysis of the solubilized phosphate by Fiskeand Subba row method daily, for a period ofa week.

b) Encapsulated forms: encapsulation of the selected variants was performed using two different substrata i.e., muslin cloth and plastic mesh (sizes 50 and $75 \mu \mathrm{m}$ ). The overnight grown isolates in sterile NB broth were considered. Individually $10 \mathrm{ml}$ of the isolates were added to the sterile Sodium alginate. The plastic meshes of different sizes were used as a carriers. The plastic mesh was dipped in inoculated sodium alginate with sterile forceps and immediately transferred to a chilled $\mathrm{CaCl}_{2}$ solution. This process was repeated thrice to build a suff icient layer of sodium alginate in the plastic mesh. Similarly, the muslin cloth was also used to immobilize the bacteria. The protocol was repeated for individual isolates. The encapsulated plastic meshes and cloth media were kept before checking active medium to check the activity of isolates.

c) Media: two different types of media were considered for assessing the efficacy of PSB. (i)The artificial medium was the soap water obtained from post-washing of the glassware in the laboratory. This media phosphate concentration was estimated prior to addition of innoculum (ii) A synthetic medium of known concentration of phosphate $(1 \mathrm{omcg} / \mathrm{ml})$ was prepared based on the standard method (Zhu et al., 2007) using Potassium dihydrogen phosphate dissolved in known volume of distilled water.

Qualitative Analysis of phosphatase enzyme: the culture was centrifuged at 2000 , rpm for 2 mins., the supernatant was used to determine the level of alkaline phosphatase and qualitatively by Kind and King's Method. The alkaline phosphatase converts phenyl phosphate to inorganic phosphate and phenol at $\mathrm{pH}$ 10. Phenol reacts in alkaline medium with 4- Amino antipyrine in the presence of the oxidizing agent Potassium Ferricyanide and forms the Orange-Red colored complex, which can be measured colorimetrically. The presence of yellowish supernatant after incubation confirms the presence of the phosphatase enzyme. The color intensity is proportional to the enzyme activity represented as KA units.

Alkaline phosphatase (KA units)=Abs. of Test - Abs. of control / Abs.ofStandard-Abs. of Blank

\section{Results:}

Overall colony-forming units for the total count varied with the sampling stations. A total of 7 isolates were initially identified on nutrient agar plates. Among which two bacterial isolates performed the ability to solubilize insoluble phosphate in the PVK agar medium with a zone of inhibition around the colonies. Such isolates (considered 
as PSBs) were further identified and assessed for the eff icacy as Phosphate solubilizers. The two isolates $-\mathrm{N}_{5}$ and N6 indicated good inhibition were Gram-negative organisms. The molecular identification of the isolates was done as suggested by standard methods. The bacterial genome has been extracted by standard methods i.e., CTAB method. The $16 \mathrm{~s}$ rRNA sequence of the isolates was identif ied. Based on the PCR analyses and BLAST similarity sequencing methods phylogeny was identified for the two variants. Clustal W multiple sequence analysis techniques were used to establish the phylogenetic tree of these PSBs (Fig.ra,b). The molecular biology-based identification techniques indicated that the two PSB species belonged to Klebsiella species.

Phosphate solubilising Efficacy: Phosphate remediation efficacy of both the bacterial species was assessed in the non - encapsulated (as inoculum) and encapsulated states using synthetic and spent media.

i) Non-encapsulated form: the soluble phosphate concentration of the synthetic medium was reduced by $\mathrm{N}_{5}$ from 0.76 to 0.48 and, N6 from, 0.76 to 0.52 . Similarly, the soluble phosphate concentration of waste-waters indicated a good reduction in phosphate concentration by $\mathrm{N}_{5}$ and $\mathrm{N} 6$ ( 2.16 to 1.44 and 2.16 to $1.36 \mu \mathrm{g} / \mathrm{ml}$ ) (Table-1). The Klebsiella $\mathrm{N}_{5}$ was more efficient in its action in synthetic phosphate and N6 in waste waters (Fig.-2).

Table 1: Percent efficiency of phosphate uptake in synthetic and wastewater media by of Klebsiella isolates N5 \& N6 in non-encapsulated forms

\begin{tabular}{lllll}
\hline Parameter & Strain & IV(Day-o) & FV (Day-7) & $\%$ Eff. \\
\hline Synthetic phosphate & $\mathrm{N}_{5}$ & 0.76 & 0.48 & 36.84 \\
medium & $\mathrm{N} 6$ & 0.76 & 0.52 & 31.57 \\
Wastewater test & $\mathrm{N}_{5}$ & 2.16 & 1.44 & 33.33 \\
medium & $\mathrm{N} 6$ & 2.16 & 1.36 & 37.07 \\
\hline
\end{tabular}
IV- Initial value of the phosphate (DAY o) in $\mu \mathrm{g} / \mathrm{ml}$; FV- Final value of the phosphate (DAY 7 ) in $\mu \mathrm{g} / \mathrm{ml}$

iia) Encapsulated form (plastic): N6 was more efficient as phosphate value reduced from 2.16 to 1.28 for Mesh 1 size and $\mathrm{N}_{5}$ was more efficient and reduced phosphate concentration from 2.16 to $1.24 \mu \mathrm{g} / \mathrm{ml}$ for mesh 2 ( Table-2). Percent efficiency of phosphate uptake of the isolates in mesh encapsulated form indicated that the Klebsiella $\mathrm{N}_{5}$ immobilized bacteria on mesh size 2 found to be effective in

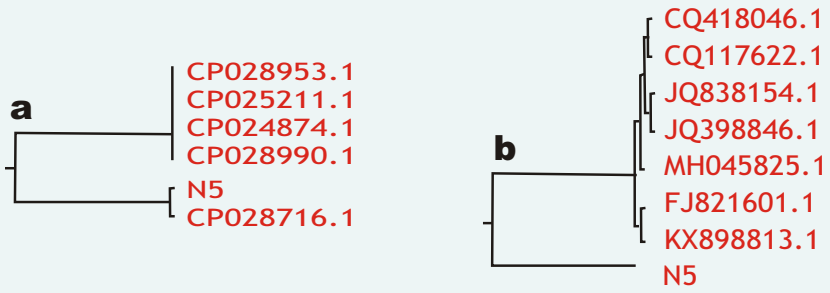

Figure-1: Neighbor-joining Rooted phylogeny tree of $\mathrm{N}_{5}$ isolate compared to Klebsiella spp based on 16S rRNA gene sequences. a) $97 \%$ Similarity index. b) $87 \%$ Similarity index. spent media from the laboratory (Fig.-3) iib) Encapsulated form (cloth): the bacteria were similarly immobilised using sodium alginate and $\mathrm{CaCl}_{2}$ on cloth to assess their efficacy as PBS using same media after a week incubation under shaker conditions at room temperature. The result of the solubilized phosphate indicated very low activity even after 7 days. The eff iciency remained lesser than $25 \%$. (Fig.-3).

Table 1: Percent efficiency of phosphate uptake in synthetic and wastewater media by of Klebsiella isolates N5 \& N6 in non-encapsulated forms

\begin{tabular}{lllll}
\hline Parameter & Strain & IV(Day-o) & FV (Day-7) & \% Eff. \\
\hline Plastic mesh 1 strip & $\mathrm{N}_{5}$ & 2.16 & 1.40 & 35.18 \\
& $\mathrm{~N} 6$ & 2.16 & 1.28 & 40.74 \\
Plastic mesh 2 strip & $\mathrm{N}_{5}$ & 2.16 & 1.16 & 46.29 \\
& $\mathrm{~N} 6$ & 2.16 & 1.24 & 42.59 \\
\hline
\end{tabular}

IV- Initial value of the phosphate (DAY o) in $\mu \mathrm{g} / \mathrm{ml}$; FV- Final value of the phosphate (DAY 7 ) in $\mu \mathrm{g} / \mathrm{ml}$

Phosphatase enzyme analysis: bacterial action on the phosphate-rich media may be due to the release of enzymes which can remediate the nutrients. Since these bacteria are capable of reducing the phosphates, the enzymes produced could be Phosphatases. In order to identify a confirmative test was performed. The results indicated that the reaction of $\mathrm{N}_{5}$ isolate only showed the presence of yellow color after incubation indicating the presence of Phosphatase enzyme. The N6 isolate didn't produce any yellow colour indicating the absence of alkaline phosphatase.

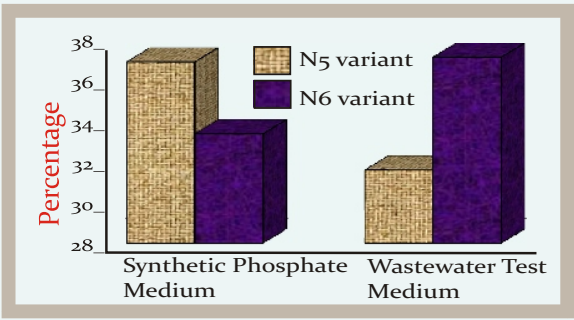

Figure-2: Percent efficiency (\%) of Phosphate uptake of the isolates in non-encapsulated form

Quantitative alkaline phosphatase enzyme analysis: the alkaline phosphatase enzyme quantitative analysis indicated variation in the production of the enzyme. Klebsiella N6 produced more quantities of phosphatase enzyme, can reduce the phosphates earlier. The phosphatase value of $\mathrm{N} 6$ (7.5 KA units) was more than $\mathrm{N}_{5}$ (2.5 KA units) after a week period. For $\mathrm{N}_{5}$, the value came to

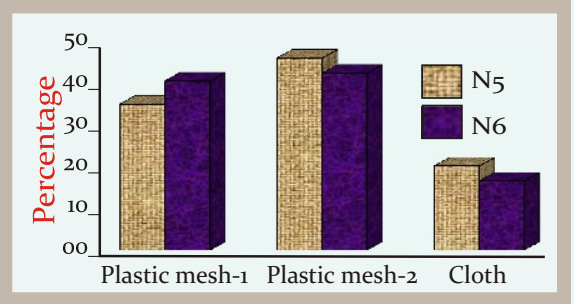

Figure-3: Bioremediation efficiency (\%) of Klebsiella isolates (N5 \& N6) encapsulated on various substrata 
be 2.5 KA units for N6, the value came to be 7.5 KA units.

The direct addition of inoculum to the synthetic phosphate medium indicated that $\mathrm{N}_{5}$ showed (36.84\%) more phosphate uptake efficiency than N6 (31.57\%). N6 (37.07\%) was more efficient than $\mathrm{N}_{5}(33.33 \%)$ for wastewater test medium. Further, the organisms were encapsulated considering the benefits of encapsulation like the longevity of the organisms, re-use of the encapsulated forms, etc using sodium alginate beads as well as mesh. With plastic mesh 1 variant, the $\mathrm{N}_{5}$ and N6 showed $35.18 \%$ and $40.74 \%$ uptake efficiency. With plastic mesh 2 variant, the $\mathrm{N}_{5}$ and $\mathrm{N} 6$ showed $46.29 \%$ and $42.59 \%$ uptake efficiency. $\mathrm{N}_{5}$ isolates were more effective in non encapsulated conditions and in synthetic media; while the N6 was efficient in the encapsulated form, irrespective of the media considered as well as non-encapsulated condition in wastewaters and test medium. A comparatively lower uptake eff iciency (20.37 and 16.66\%) was noticed for the $\mathrm{N}_{5}$ and $\mathrm{N} 6$ isolates when immobilized on a muslin cloth than the other non-encapsulated and encapsulated forms. The probable reason can be the disappearance of the sodium alginate layer on the muslin cloth. Overall the alkaline phosphatase enzyme of $\mathrm{N}_{5}$ proved to be more effective in mesh 2 and cloth substrates based immobilized conditions.

\section{Discussion:}

Research on phosphate solubilizing bacteria has tremendous importance not only with respect to remediation purposes but also for industrial applications, as they can synthesize different types of acids. Marine environments are naturally equipped with biota capable of maintaining the coastal shores irrespective of the anthropogenic activities resulting in polluted environments. The two isolated PSBs wereassessed for their exclusive efficient way of reducing phosphates. The phosphate isolates in non-encapsulated form showed efficient solubilizing activity in both synthetic medium as well as an artificial medium. K.pneumoniae isolated from the estuarine waters and sediments of the Matang mangrove estuary (Anis et al., 2016) which showed its pathogenic conditions. Earlier studies have indicated that Klebsiella spp. are one of the Phosphate solubilizing bacteria in the terrestrial environment (Chung et al., 2005). This study indicated that PSBs isolated and identified from the marine sandy beaches of Mumbai comprise 2 variants of Klebsiella spp. Encapsulated beads and plastic mesh-based alginate encapsulation method for both the Klebsiella variants found to be more effective and efficient modes than the muslin cloth. The sizes of the plastic mesh could be an essential factor for exchange of the medium and nutrients for the organisms.

Conclusively, research on probiotics is a promising study as there is an increasing demand to protect our ecosystems irrespective of their aquatic or terrestrial conditions. The understanding of bacteria that can be used as probiotics requires intense and knowledge-based research and development of novel technologies to introduce and keep them active in order to improve their activity. This study shed some light to develop aquaprobiotic systems to biodegrade and treat phosphate-rich wastewaters.

\section{Acknowledgements:}

We thank the SVKM management for providing wonderful working conditions and our Principal Dr.Rajpal Shripat Hande for his constant support and encouragement..

\section{References:}

Ahamed, N. \& Shahab, S. (2009): PhosphateSolubilization: Their Mechanism Genetics And Application. Internet J. Microbiol., 9(1):1-19.

Audipudi, A.V., Kumar, N.P. \& Sudhir, A. (2012): Phosphate solubilizing microorganisms associated with Chollangi mangrove soil in east coast of India. Int. J. Sci. Eng. Res., 3(11):2229-5518.

Ayyakkannu, K. \& Chandramohan, D. (1970): On the occurrence and distribution of phosphobacteria in the marine environment at Porto Novo. Current Sci., 17:398-399.

Barati, A., Ghaderpour, A., Chew, L.L., Bong, C.W., Thong, K.L., Chong, V.C., Chai, L.C. (2016): Isolation and Characterization of Aquatic-Borne Klebsiella pneumoniae from Tropical Estuaries in Malaysia. Int. J. Environ. Res. Public. Health, 13(4):426.

Chung, H., Park, M., Madhaiyan, M., Seshadri, S., Song, J., Cho, H. \& Sa, T. (2005): Isolation and characterization of phosphate solubilizing bacteria from the rhizosphere of crop plants of Korea. Soil Biol. Biochem., 37(10):1970-1974.

Das S., Lyla, P.S. \& Khan, S.A. (2007): Biogeochemical processes in the continental slope of Bay of Bengal: I. Bacterial solubilization of inorganic phosphate. Rev. Biol. Trop., 55(1):1-9.

De Souza, M.J.B.D., Nair, S. \& Chandramohan, D. (200o): Phosphate Solubilizing bacteria around the Indian Peninsula. Indian J. Mar. Sci., 29(1):48-51.

De, T.K., Sarkar, T.K., De, M., Maity, T.K., Mukherjee, A. \& Das, S. (2011): Abundance and occurrence of phosphate solubilizing bacteria and phosphatase in sediment of Hooghly estuary, northeast coast of Bay of Bengal, India. J. Coastal Dev., 15(1):916.

Dyhrman, S.T., Ammerman, J.W., Benjamin, A.S. \& Van Mooy, B.A.S.(2006): Microbes and the Marine Phosphorus Cycle, Microbes and Major Elemental Cycles. Oceanography. 20(2):110-116.

Fiske, C.H. \& Subbarow, Y. (1925): The colorimetric determination of Phosphorus.J. Biol. Chem., 66(2):375-400.

Illmer, P. \& Schinner, F. (1995): Solubilization of inorganic calcium Phosphate-solubilization mechanisms. Soil. Biol. Biochem. 27(3):257-263.

Kalayu, G. (2019) Phosphate solubilizing microorganisms: promising approach as biofertilizers. Int. J. Agron., Article ID 4917256:1-7.

Kannapiran, E. \& Sri Ramkumar, V. (2011): Isolation of phosphate solubilizing bacteria from the sediments of Thondi coast, 
Palk Strait, Southeast coast of India. Ann. Bio. Res., 2(5):157163.

Maitra, N., Bandopadhyaya, C., Samanta, S. \& Manna, S.K. (2014): Isolation, identification and efficacy of inorganic phosphate solubilizing bacteria from oxbow lakes of West Bengal, India. Geomicrobiol.J., 32(8):751-758.

Mamatha, S.S., Gobika, A. \& Janani, P. (2012): Phosphate solubilizing bacteria and alkaline phosphatase activity in coastal waters off Trivandrum. L. Coastal Environ., 3(1):90100.

Martínez, S.A.D. \& Yaneth, A.B-T. (2009): Biodegradation of wastewater pollutants by activated sludge encapsulated inside calcium-alginate beads in a tubular packed bed reactor. Biodegradation, 20(5):709-715.

Paul, D. \& Sinha, S.N. (2017): Isolation and characterization of phosphate solubilizing bacterium Pseudomonas aeruginosa KUPSB12 with antibacterial potential from river Ganga, India. Ann. Agrarian Sci., 15(1):130-136.

Sahu, M.K., Sivakumar, K., Thangaradjo, T. \& Kannan, L. (2007): Phosphate solubilizing actinomycetes in the estuarine environment: An inventory. L. Environ. Biol., 28(4):795-798.

Sambrook, J. \& Russell, R.W. (2001): Molecular cloning: a laboratory manual, 3rd ed. Pub. by: Cold spring harbor laboratory press, Cold Spring harbor, N.Y.P.
Sergio, A.M. \& Bustos, T.Y. (2009): Biodegradation of wastewater pollutants by activated sludge encapsulated inside calciumalginate beads in a tubular packed bed reactor. Biodegradation, 20(5):709-715.

Vazquez, P., Holguin, G., Puente, M.E., Lopez-Cortes, A. \& Bashan, Y. (2000): Phosphate-solubilizing microorganisms associated with the rhizosphere of mangroves in a semiarid coastal lagoon. Biol. Fert. Soils., 30(5-6):46o-468.

Yulianti, E. \& Rakhmawati, A. (2017): Screening and characterization of phosphate solubilizing bacteria from isolate of thermophilic bacteria. Pub. in: AIP Conference Proceeding. 1868(1): 090015.

Zhou, C., Song, C., Huang, D., Liu, Y., Cao, X. \& Zhou, Y. (2011): Isolation and Characterization of Organic PhosphorusMineralizing Bacteria in Sediment of a Chinese Large Shallow Eutrophic Lake (Lake Taihu). Geomicrobiol. J., 28(8):66o666.

Zhu, F., Qu, L., Hong, X. \& Sun, X. (2011): Isolation and characterization of a phosphate-solubilizing halophilic bacterium Kushneria sp. YCWA18 from Daqiao Saltern on the coast of Yellow Sea of China.?Evidence-Based Comple. Alter. Med., Article ID 615032:1-6. 